\title{
No demos portazos
}

\author{
Dr. Gerardo Soca Cariboni, \\ Editor-jefe de la Revista Uruguaya de Cardiología
}

El nacimiento y la muerte son procesos biológicos naturales que marcan el inicio y el final de nuestro tiempo sobre la tierra.

Vida y muerte son parte de una misma unidad y su conceptualización es un proceso personal, íntimo, particular de cada uno, que nos acompaña de distintas maneras en forma permanente durante ese tránsito.

Podríamos afirmar, además, que dicha conceptualización está vinculada a múltiples factores culturales, sociales, familiares, geográficos y también a la edad y el tiempo histórico en el que nacimos, el nivel educativo e intelectual, las creencias y las experiencias de vida, entre las que incluimos nuestra profesión.

Mi condición de médico y el haber trabajado los primeros 30 años de la carrera en unidades de terapia intensiva ha marcado de manera importante mis percepciones acerca de la vida y la muerte.

Como conocemos, estas unidades concentran a pacientes graves que tienen, por definición, inestabilidad de un sistema fisiológico mayor que potencialmente los puede llevar a la muerte. En la época en que me inicié en esa especialidad, la mortalidad global de los pacientes que ingresaban a terapia intensiva era de aproximadamente $30 \%$. Es decir, uno de cada tres pacientes fallecía. Aunque las cifras pueden ser variables dependiendo del tipo de unidad (cardiológica, neurológica, de trauma, etc.) y de los criterios de ingreso, la muerte es un hecho cotidiano al cual deben enfrentarse quienes allí trabajan.

Este hecho, más allá de lo que se puede pensar, no banaliza el tema, sino que genera en todos, con diferentes sensibilidades y aun sin explicitarlo, un proceso intelectual personal de aprendizaje y asimilación del fenómeno.

Dentro de las muchas experiencias vividas, una en particular me ha resultado inolvidable, quizá porque yo tenía en ese momento la misma edad de la paciente.

Me tocó asistir a una señora de 36 años, con hijos pequeños, "sana” hasta horas previas, que ingresó por una hemorragia cerebral grave, por rotura de aneurisma, con criterios clínicos de muerte cerebral. Pocas horas después, la paciente falleció.

En estos días la muerte ha pasado a ser un tema cotidiano de conversación en la familia, con los amigos, en los medios, en las redes.

Todos hablamos y hasta contamos y comparamos las personas fallecidas por determinada enfermedad.

La muerte, aunque siempre presente, de ser un tema que por simple espíritu de sobrevivencia no ocupa explícitamente en nuestra agenda el primer plano, por imperio de los hechos ha pasado a hacerlo.

Muchos pilares culturales de nuestra sociedad occidental nos llevan actualmente a percibirla siempre a distancia, algo que sucede a otros, o en otro lado, o en otros países. Cuesta concebirla como parte inseparable de la vida.

Hasta hace no muchos años, era considerada un fenómeno natural y asumida de manera más sencilla. O era algo dependiente de fuerzas superiores, dioses, que determinaban la vida, la muerte y la evolución de la naturaleza. Las terribles epidemias eran consideradas castigos divinos.

Actualmente predomina en muchas personas la idea de que la muerte es siempre evitable, o que no debería haber ocurrido, o que es culpa de algo o alguien.

Aun en esta pandemia gran parte de la sociedad piensa que solo mueren los viejos y enfermos.

A veces inconscientemente somos permeables a la idea de que los progresos de la ciencia y la tecnología nos permitirán alcanzar la vida eterna. Los apabullantes avances científicos y tecnológicos nos impulsan a soñar con la inmortalidad, aunque por ahora no es más que una utopía.

Recibido Jun 16, 2020; aceptado Jun 23, 2020. 
Estamos viviendo un momento muy particular de la historia de la humanidad y sería importante extraer de esta crisis aspectos positivos que nos ayuden a mejorar como seres humanos.

Más allá que los progresos de la ciencia nos permiten hoy día tener una expectativa de vida significativamente mayor que unas décadas atrás, la muerte debe valorarse como un hecho natural, como parte inseparable de la vida, tal como la ha concebido la humanidad hasta el momento.

Deberíamos tener presente nuestra fragilidad (todos podemos tener un aneurisma), la idea de la finitud de la vida.

Pero más allá de ser algo angustiante y paralizante, debería ser una motivación que nos ayude a disfrutar y valorar lo que tenemos.

No lo que quisiéramos tener o soñamos con tener, sino lo realmente importante por sobre lo descartable o prescindible. Los afectos, la familia, la amistad, jerarquizar los valores humanistas de solidaridad y fraternidad, y tener una mayor empatía con el menos favorecido o sufriente.

En definitiva, ser más humanos.

La paciente, como mencioné, falleció a las pocas horas. Como corresponde, debía informar a sus familiares del desenlace. Estaba su esposo, y recuerdo, como si fuera hoy, en aquel corredor poco iluminado, su cara de dolor, de angustia, de miedo ante mis palabras.

Quedó en silencio un rato y lo único que me dijo fue: "Y pensar que hoy de mañana discutimos por una banalidad y me fui de casa con un portazo".

Hizo una pausa, me dio la mano, se dio media vuelta y se retiró.

Pongamos nuestras prioridades en orden, traigamos a la superficie lo que debe estar en ella, no perdamos el tiempo en banalidades, disfrutemos de la vida, seamos más y más solidarios y fraternos.

El tiempo del que dispongamos, lo transitaremos y lo utilizaremos así de la mejor manera posible.

Cuando ocurra lo inexorable, no tendremos nada para reprocharnos.

\section{Dr. Walter Reyes Caorsi \\ Comisión Honoraria para la Salud Cardiovascular. Montevideo, Uruguay.}

Walter Reyes Caorsi, https://orcid.org/0000-0002-4670-5765 